\title{
Assessment of the GPM IMERG and CHIRPS precipitation estimations for the steppe region of the Crimea
}

\author{
Victor F. Popovych \\ Research Institute of Agriculture of Crimea, e-mail: water@crimea.com \\ Ielizaveta A. Dunaieva \\ Research Institute of Agriculture of Crimea, e-mail: water_crimea@hotmail.com
}

\begin{abstract}
This paper compares the spatial distribution datasets on monthly precipitation totals derived from the Famine Early Warning System Network FEWS NET service (CHIRPS 2.0 product) and the International Mission of the Global Precipitation Measurement GPM (IMERG v06 product) with ground-based observations of a stationary weather stations located in the steppe region of the Crimean Peninsula in order to assess the representativeness of the precipitation spatial distribution and the applicability of the datasets for water balance calculations and agricultural crop dynamics modeling. A close convergence was observed between the estimated monthly precipitation totals and the precipitation gauge data during the study period (January 2017 - July 2020), with mean correlation coefficients of 0.75 and 0.73 for the GPM IMERG and CHIRPS, respectively. Both products generally overestimated the precipitation values compared to the measured data, with GPM IMERG (final run) exhibiting the greatest overestimations (1.3-2.1 times the weather station values). Our results demonstrate the requirement of GPM-derived precipitation estimations (particularly those from the GPM_3IMERDL v06 daily accumulated late run dataset) to be additionally verified and calibrated based on data from regional weather stations or the CHIRPS 2.0 product (if available).
\end{abstract}

Keywords

Precipitation, open source data, GPM IMERG, CHIRPS, weather station, local level, agriculture, the Crimea.

Submitted 10 October 2020, revised 6 January 2021, accepted 4 February 2021

DOI: $10.26491 / \mathrm{mhwm} / 133088$

\section{Introduction}

The amount of precipitation over a certain period of time is the principle limiting factor for crops growing in rainfed agriculture conditions across arid zones. The level of initial moisture content in a particular field (at sowing or seedling emergence) is typically employed as an initial parameter in crop modeling and is determined via field surveys (estimated moisture from soil samples or soil moisture sensors), water balance calculations based on the agrohydrological modeling of the preceding period and remote sensing (RS) data. The spatial resolution of the data services that provide soil moisture information from the upper 3$5 \mathrm{~cm}$ soil layer and the layer up to $1 \mathrm{~m}$ are currently relatively low, at approximately $25 \times 25 \mathrm{~km}$ and $10 \times 10 \mathrm{~km}$ respectively, with data delays from 3 days up to 3 months (Karthikeyan et al. 2017; Yee et al. 2017). Such resolutions allow for the application of the datasets in global modeling, but not for their direct usage in the monitoring and forecasting of tasks in the field. Furthermore, in arid zones, particularly in rainfed conditions, precipitation can be highly variable, the measurement accuracy of which, its spatial and temporal variation, often determines the accuracy of water balance calculations and crop growth simulation results. 
One of the most significant achievements of the last two decades in global precipitation measurements has been the Tropical Rainfall Measuring Mission (TRMM) (Liu et al. 2012), a joint project between NASA and the Japan Aerospace Exploration Agency (JAXA). TRMM was originally intended to run for 3 years, yet it was deployed for more than 15 years (1997-2015). During this mission, many developments, basic algorithms and global approaches were determined to assess the interrelation of the atmospheric processes connected with the water cycle, including the application of microwave radiometers for precipitation measurements (Ebert et al. 2007; Huffman et al. 2007; Liu, Zipser 2015). Despite the significant raster size of the precipitation fields (spatial resolution $0.25^{\circ}$ or approx. $500 \mathrm{~km}^{2}$ for the steppe territory of the Crimean Peninsula, with a temporal resolution of 3 hours), numerous studies have been performed to assess the accuracy of satellite-derived precipitation data (Chokngamwong, Chiu 2008; Scheel et al. 2011; Chen et al. 2020). A particularly important area of research is the application of satellite data to solve hydrological tasks (i.e., river water resource management) using the basin approach (Kidd et al. 2009; Liu et al. 2015).

The scientific and technological developments of the TRMM mission were subsequently employed during the preparation of the new Global Precipitation Measurement (GPM) mission (Hou et al. 2014), which began in 2014. The satellites and data integration methods used in this mission increased the spatial and temporal accuracy of the data, with corresponding resolutions of $0.1^{\circ}$ and $30 \mathrm{~min}$, respectively (Wang et al. 2018). This spatial resolution (grid area $85.8 \mathrm{~km}^{2}$ ) is comparable to the average area of a rural settlement in the steppe Crimea $\left(95 \mathrm{~km}^{2}\right)$ and exceeds the average area per stationary weather station in the Crimea (i.e., on an area of approx. $1,700 \mathrm{~km}^{2}$ ). This allows for (considering data availability), more than 20 additional georeferenced precipitation estimations averaged for the area of each grid across the central Crimea district. Primary raster precipitation data decomposition using data from satellite imagery was developed within the Famine Early Warning System Network (FEWS NET) project and can represent fields of estimated precipitation distributions with a raster size of $0.05^{\circ}$ (Funk et al. 2014). This spatial resolution surpasses that of the GPM mission (GPM IMERG dataset). The technology has been developed since 1999 by scientists from the University of California in collaboration with the U.S. Geological Survey (USGS) in order to produce precipitation geo-referenced grids, which are particularly important in sparse data regions. The current version of the methodological approach includes data from weather stations and precipitation gauge posts, spatial variation modelling of precipitation interrelated with the terrain, and data from the satellite monitoring of precipitation. This methodology is primarily focused on the monitoring and forecasting periods of severe drought or floods in order to develop measures to mitigate their impact. Its application range is wide and the supported geospatial database of numerous meteorological parameters, including precipitation, continues to be verified in various regions across the world (Funk et al. 2015; Paredes-Trejo et al. 2017; Dinku et al. 2018; Saeidizand et al. 2018).

Multiple approaches are used to test the Integrated Multi-satellitE Retrievals for GPM (IMERG) and FEWS - the Climate Hazards Group InfraRed Precipitation with Station (CHIRPS), including direct comparisons with ground-based data on measured precipitation (Ning et al. 2016; Nashwan et al. 2019; 
Satgé et al. 2019); cross-comparisons with other products and ground-based data (Wang et al. 2018; Beck et al. 2019; Xiao et al. 2020); and indirect estimations obtained by assessing the accuracy of runoff models (Pang et al. 2020). The generalized analysis of these publications demonstrates that in most cases, several factors (topographic features, wet or arid regions, winter or summer periods, frequency of extreme precipitation events, etc.) prevent the selection of the optimal database or methodology (Tang et al. 2020; Xiao et al. 2020).

The technologies for remote precipitation measurements are constantly improving, with sampling times of $30 \mathrm{~min}$ (and more) and high spatial resolutions of $0.05-0.1^{\circ}$, allowing their application in seasonal planning and regional analysis tasks, as well as their integration with additional ground-based observations for technological decisions at the field level. The necessity of such information is primarily caused by the low number of stationary and automated weather stations in some regions, as well as the practical impossibility of obtaining regular spatial data of measured precipitation from "field" precipitation gauges (particularly in winter with snowfall).

The aim of this study is to compare the accuracy of spatial field precipitation estimations obtained via the GPM IMERG and FEWS CHIRPS products, with gauge-based precipitation data employed for spatial agro-technological monitoring and planning. We hypothesize the potential difference in the relationship between the precipitation data of the RS products and the ground observations of the weather stations, which have different levels of data accessibility for end users (free open access or limited by price, continuity, etc.).

The level of applicability of the products for agricultural areas within the steppe region of the Crimean Peninsula is demonstrated by comparing the usage of gauge precipitation data from weather stations, GPM mission data (GPM IMERG v06 products - GPM_3IMERGM, final run and GPM_3IMERGDL late run datasets) and the early warning system of extreme situations FEWS NET (CHIRPS 2.0 product).

\section{The study area}

The Crimean Peninsula is located between $44^{\circ} 38^{\prime}$ and $46^{\circ} 15^{\prime}$ latitude, $32^{\circ} 48^{\prime}$ and $36^{\circ} 65^{\prime}$ longitude and is surrounded by the Black and Azov seas almost from all sides. According to the integrated indicators of agro-climatic resources, the territory of the peninsula is divided into 4 zones: steppe; foothills; mountain; and southern coast. The Crimean steppe region occupies almost $75 \%$ of the peninsula territory and is characterized as semiarid prairie land. This zone is located between temperate (the northern and central part of the Crimea) and subtropical (the southern part of the peninsula, which is protected from a colder climate by the Crimean mountains) climate belts. The climate of the steppe plains is continental and moderately warm. The average annual air temperature is $11.0^{\circ} \mathrm{C}$, ranging from 10.3 to $11.8^{\circ} \mathrm{C}$, while the average annual precipitation in the central zone of the steppe is approximately $450 \mathrm{~mm}$ (Klepynine weather station, no. 6 in Fig. 1). The amount of precipitation throughout the steppe varies (spatially) from 366 to $484 \mathrm{~mm}$ on average per year, and from 200 to $773 \mathrm{~mm}$ over the years for the weather stations of the steppe zone. 


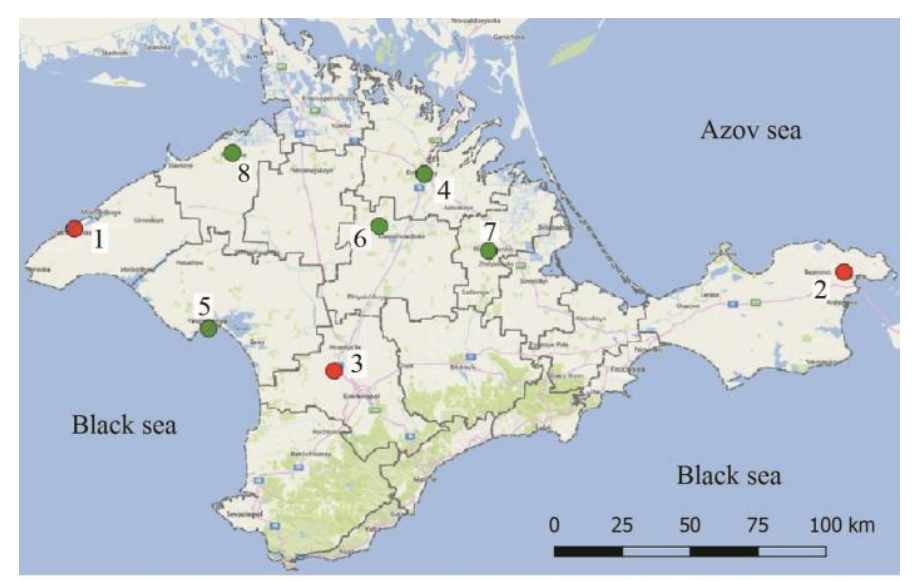

Legend: 1 WMO and other analized regional weather stations District border $1,2, \ldots$ weather station number

Fig. 1. Location of the weather stations used for analysis in the territory of the Crimean Peninsula.

A total of 8 weather stations were selected to carry out a comparative analysis of the RS-estimated precipitation with ground-based observations. Their zone of representativeness covers almost the entire territory of the Crimean steppe zone (Fig. 1). Data from 3 weather stations are available (free open access to longterm continual daily data) from the databases associated with the World Meteorological Organization (WMO). Table 1 reports the details of the weather stations used in the analysis.

Table 1. Weather stations characteristics.

\begin{tabular}{|c|c|c|c|c|}
\hline No & Station ID* & Name & Elevation $[\mathrm{m}]$ & Data availability status \\
\hline 1 & 339240 & Chornomorske & 7 & \multirow{3}{*}{ Free open access through the WMO network } \\
\hline 2 & 339830 & Kerch & 45 & \\
\hline 3 & 339460 & Simferopol & 177 & \\
\hline 4 & 339340 & Dzhankoy & 9 & \multirow{5}{*}{$\begin{array}{l}\text { Partially available as free open access data } \\
\text { through weather informer }\end{array}$} \\
\hline 5 & 339290 & Yevpatoriya & 5 & \\
\hline 6 & 339390 & Klepynine & 36 & \\
\hline 7 & 339620 & Nyzhniohirsk & 20 & \\
\hline 8 & 339220 & Razdolnoe & 17 & \\
\hline
\end{tabular}

* National Climatic Data Center (NCDC) weather station number.

The weather stations listed in Table 1 are grouped as "WMO" and "regional' stations. Note that "regional" stations also have ID station numbers and use the same equipment for precipitation measurements as the "WMO" stations.

\section{Materials and methods}

GPM datasets on the spatial distribution of monthly precipitation totals for Crimea territory collected between January 2017 and July 2020 were downloaded using the Giovanni service ${ }^{1}$, according to the FEWS

\footnotetext{
${ }^{1}$ https://giovanni.gsfc.nasa.gov/ GPM_3IMERGM v06 merged satellite-gauge precipitation monthly dataset, the final run; and the late run for last 3 months of the analyzed period used daily accumulated precipitation estimations - GPM_3IMERDL v06, spatial resolution $0.1^{\circ}$.
} 
Network ${ }^{2}$, ground data of daily precipitation totals are taken from the data of the open archive of the Rp5 weather informer ${ }^{3}$ and WMO related the National Climatic Data Center database ${ }^{4}$.

Raster images of precipitation distribution fields for the Crimean Peninsula derived from GPM IMERG and CHIRPS were read in GeoTIFF format. The numerical values of precipitation were read from the grids corresponding to the weather stations locations and written to the vector weather station layer (using the QGIS 3.10 point sampling plugin).

In order to analyze the convergence between the weather station data and the estimated values of the GPM_3IMERG and CHIRPS products, we employed the following statistics for monthly precipitation totals across January 2017 - July 2020: the bias, which represents the overestimation (>1) or underestimation of the measured parameter $(<1)$; the mean error $(\mathrm{ME})$ or difference, where positive/negative values indicate the average overestimation/underestimation per month compared to the basic parameter $(\mathrm{mm})$; the root mean square error (RMSE) or standard deviation shows the level of precipitation variation in physical units $(\mathrm{mm})$ over the months; the Pearson correlation coefficient $(r)$ and coefficient of determination $\left(r^{2}\right)$ characterize the strength of relation or dependence between compared parameters (commonly used qualitative characteristics for different $r$ levels are 0.40-0.59 "moderate", 0.60-0.79 "strong", 0.80 and higher "very strong", or "functional" if $r=1.0)$; the Nash-Sutcliffe efficiency coefficient (NSe) is used for the accuracy estimation of the RS products compared to the ground based observations, where the closer the value is to one the higher the association between the measured precipitation and satellite estimations, and a zero value indicates that the predictive properties of the satellite estimations are equal to the forecast (Dembélé, Zwart 2016).

The average (AVG) and maximum and minimum (MAX and MIN) values of the measured and estimated monthly precipitation totals were also employed to analyze the differences in their absolute values during the analyzed period. The aforementioned statistics were calculated as follows:

$$
\begin{aligned}
& \text { Bias }=\sum P_{R S} / \sum P_{M}, \\
& M E=\frac{\sum P_{R S}-\sum P_{M}}{n}, \\
& R M S E=\left(\frac{\sum\left(P_{i}-P_{a v}\right)^{2}}{n-1}\right)^{0.5}, \\
& r=\frac{\sum\left(P_{R S}-P_{a v}^{R S}\right) \cdot\left(P_{M}-P_{a v}^{M}\right)}{\left(\sum\left(P_{R S}-P_{a v}^{R S}\right)^{2} \cdot \sum\left(P_{M}-P_{a v}^{M}\right)^{2}\right)^{0.5}}
\end{aligned}
$$

\footnotetext{
${ }^{2}$ https://earlywarning.usgs.gov/fews/ The Climate Hazards Group InfraRed Precipitation with Station, CHIRPS, algorithm and dataset CHIRPS 2.0, gridded with $0.05^{\circ}$ resolution.

${ }^{3}$ https://rp5.ru/

4 ftp://ftp.ncdc.noaa.gov/pub/data/gsod
} 
$N S e=1-\frac{\sum\left(P_{R S}-P_{M}\right)^{2}}{\sum\left(P_{M}-P_{a v}^{M}\right)^{2}}$,

$r=\frac{\sum\left(P_{R S}-P_{a v}^{R S}\right) \cdot\left(P_{M}-P_{a v}^{M}\right)}{\left(\Sigma\left(P_{R S}-P_{a v}^{R S}\right)^{2} \cdot \sum\left(P_{M}-P_{a v}^{M}\right)^{2}\right)^{0.5}}$ where $P_{i}$ and $P_{a v}$ are the sum precipitation per month $i$ and the averaged value of monthly precipitation totals, respectively $[\mathrm{mm}] ; P_{M}$ and $P_{R S}$ are the monthly precipitation totals, measured and estimated by RS, respectively [mm]; $P M_{a v}$ and $P R S_{a v}$ are the averaged value of the monthly precipitation totals measured and estimated by RS, respectively [mm]; and $n$ is the total number of months.

The determination coefficient $\left(r^{2}\right)$ was determined as the square of the correlation coefficient. The leastsquares method was applied for the calculation of the linear regression coefficients.

\section{Results}

We compared the monthly precipitation total for the period of January 2017 - July 2020 in order to assess the strength of the association between the precipitation data derived from the RS methods (GPM IMERG and CHIRPS) and the ground-based observation data from the weather station network. Figure 2 presents the relationship between the measured and estimated values of monthly precipitation totals. The blue and green weather stations denote those with freely available data through the WMO network and several other regional weather stations of the steppe region in the Crimea, respectively. The y-axis provides information on the RS monthly precipitation totals while the $\mathrm{x}$-axis presents the equivalent data from the weather stations.

Both RS products exhibit a significantly higher correlation with the WMO network weather station data (average determination coefficients are 0.65 and 0.62 ) than with other regional stations, with average $r^{2}$ values of 0.51 and 0.49 for the GPM IMERG and CHIRPS products, respectively.

The GPM IMERG product exhibits the highest correlation with the ground-based data, with $r^{2}$ values of 0.67 and 0.71 ("very strong") for the Kerch and Simferopol stations, respectively. The lowest correlations were determined between CHIRPS and the Dzhankoy station $\left(r^{2}=0.29\right.$, "moderate" level). The remaining stations exhibited a "strong" correlation, with coefficients of determination ranging from 0.41 to 0.63 .

A direct comparison between the ground data (measured at the individual points of the rain gauge location) with model estimations of the precipitation values averaged over the pixel area $\left(0.1^{\circ}\right.$ or approx. 85.8 $\mathrm{km}^{2}$, and $0.05^{\circ}$ or $21.4 \mathrm{~km}^{2}$ for GPM IMERG and CHIRPS, respectively) is not entirely correct. However, taking into account that the same approach is used to compare the correlation between both products, this disadvantage in the methodological approach can be neglected. Table 2 reports the resulting statistical indicators of the analysis. 


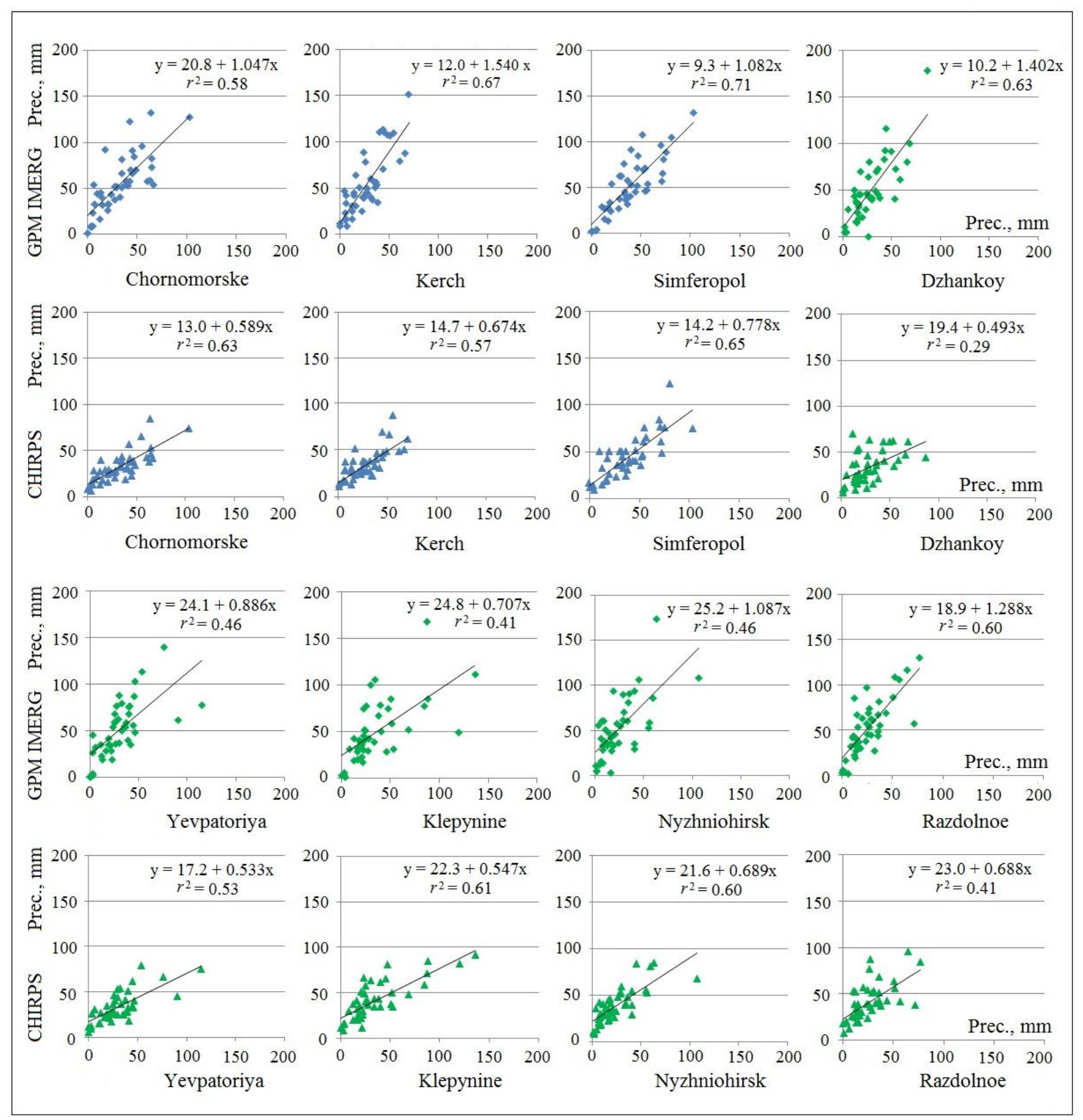

Fig. 2. Relationship between weather station precipitation data and equivalent RS estimations (GPM MERG, final run and CHIRPS). Blue - WMO network; green - regional stations.

The average amounts of the monthly precipitation for the entire study period across weather stations determined by the stations, GPM IMERG and CHIRPS were $30.4 \mathrm{~mm}, 52.0 \mathrm{~mm}$ and $37.2 \mathrm{~mm}$, respectively, while the latter two overestimated the ground-based measurements by 21.6 and $6.8 \mathrm{~mm}(\mathrm{ME})$ per month. The absolute deviations of the minimum RS monthly precipitation estimations from the equivalent weather station values (MIN) are low, ranging from 0.4 to $8.3 \mathrm{~mm}$ and 4.0 to $9.7 \mathrm{~mm}$ for GPM IMERG and CHIRPS, respectively. Moreover, the minimum values determined from CHIRPS exceed those of the ground-based and GPM values for all weather stations. 
The absolute deviations of the maximum RS monthly precipitation estimations from those measured at weather stations (MAX) are significant for both products, varying within 25.0-91.5 mm and 15.4-45.1 mm for GPM IMERG and CHIRPS, respectively. The CHIRPS product exhibits both positive and negative deviations, while the GPM IMERG product presents consistent excess values. This can be observed in Figure 3, which depicts the variations in the measured and estimated monthly precipitation totals.

Table 2. Comparison of satellite and ground-based precipitation estimations between January 2017 and July 2020 .

\begin{tabular}{|c|c|c|c|c|c|c|c|c|c|}
\hline \multirow{2}{*}{$\begin{array}{l}\text { Station } \\
\text { no. }\end{array}$} & \multirow{2}{*}{$\begin{array}{l}\text { Data } \\
\text { source }\end{array}$} & \multicolumn{5}{|c|}{ Precipitation statistics [mm] } & \multirow{2}{*}{$\mathrm{r}$} & \multirow{2}{*}{ Bias } & \multirow{2}{*}{ NSe } \\
\hline & & AVG & MAX & MIN & RSME & $\mathrm{ME}$ & & & \\
\hline \multirow{3}{*}{1} & Station & 33.2 & 103.0 & 0.0 & 22.2 & - & - & - & - \\
\hline & GPM & 55.5 & 132.3 & 1.0 & 30.6 & 22.4 & 0.76 & 1.68 & -0.85 \\
\hline & CHIRPS & 32.6 & 84.5 & 6.5 & 16.5 & -0.6 & 0.79 & 0.98 & 0.63 \\
\hline \multirow{3}{*}{2} & Station & 27.9 & 70.7 & 0.5 & 18.0 & - & - & - & - \\
\hline & GPM & 55.0 & 151.1 & 8.8 & 33.9 & 27.1 & 0.82 & 1.97 & -2.75 \\
\hline & CHIRPS & 33.5 & 86.1 & 10.1 & 16.2 & 5.6 & 0.75 & 1.20 & 0.45 \\
\hline \multirow{3}{*}{3} & Station & 38.5 & 103.5 & 0.0 & 23.7 & - & - & - & - \\
\hline & GPM & 51.0 & 131.2 & 1.5 & 30,4 & 12.5 & 0.84 & 1.32 & 0.23 \\
\hline & CHIRPS & 44.2 & 122.7 & 9.7 & 22.8 & 5.7 & 0.81 & 1.15 & 0.57 \\
\hline \multirow{3}{*}{4} & Station & 28.6 & 86.4 & 1.6 & 19.0 & - & - & - & - \\
\hline & GPM & 50.2 & 177.9 & 0.3 & 33.5 & 21.6 & 0.80 & 1.76 & -1.62 \\
\hline & CHIRPS & 33.4 & 70.8 & 5.6 & 17.6 & 4.9 & 0.53 & 1.17 & 0.07 \\
\hline \multirow{3}{*}{5} & Station & 30.3 & 114.6 & 0.0 & 23.0 & - & - & - & - \\
\hline & GPM & 51.0 & 139.6 & 0.4 & 30.0 & 20.6 & 0.68 & 1.68 & -0.75 \\
\hline & CHIRPS & 33.3 & 78.8 & 5.6 & 16.7 & 3.0 & 0.73 & 1.10 & 0.52 \\
\hline \multirow{3}{*}{6} & Station & 34.8 & 136.3 & 0.1 & 30.0 & - & - & - & - \\
\hline & GPM & 49.4 & 167.9 & 1.1 & 33.1 & 14.6 & 0.64 & 1.42 & -0.05 \\
\hline & CHIRPS & 41.3 & 90.9 & 7.5 & 21.0 & 6.5 & 0.78 & 1.19 & 0.55 \\
\hline \multirow{3}{*}{7} & Station & 24.3 & 106.9 & 0.9 & 20.9 & - & - & - & - \\
\hline & GPM & 51.7 & 173.9 & 2.8 & 33.6 & 27.3 & 0.68 & 2.12 & -2.14 \\
\hline & CHIRPS & 38.4 & 85.1 & 8.7 & 18.6 & 14.1 & 0.77 & 1.58 & 0.12 \\
\hline \multirow{3}{*}{8} & Station & 26.0 & 76.8 & 0.4 & 18.5 & - & - & - & - \\
\hline & GPM & 52.4 & 129.6 & 2.2 & 30.7 & 26.4 & 0.77 & 2.01 & -2.28 \\
\hline & CHIRPS & 40.9 & 94.8 & 7.3 & 19.9 & 14.9 & 0.64 & 1.57 & -0.45 \\
\hline \multirow{3}{*}{ Average } & Station & 30.4 & 99.9 & 0.8 & 21.9 & - & - & - & - \\
\hline & GPM & 52.0 & 150 & 2.3 & 32.0 & 21.6 & 0.75 & 1.75 & -1.28 \\
\hline & CHIRPS & 37.2 & 89.3 & 7.6 & 18.7 & 6.8 & 0.73 & 1.24 & 0.31 \\
\hline
\end{tabular}

The magnitude of the precipitation variations per month, characterized by the RSME value, is equal to $21.9 \mathrm{~mm}$ for meteorological stations on average and variations ranging between 18.0 and $30.0 \mathrm{~mm}$ across the study period. The CHIRPS estimations exhibit slightly lower values for 7 out of 8 stations, with an average RSME of $18.7 \mathrm{~mm}$ and variations within 16.2-22.8 $\mathrm{mm}$. An average value of RMSE, according to the data of the GPM IMERG product, is equal to $32.0 \mathrm{~mm}$ (range of $30.0-33.9 \mathrm{~mm}$ ), and exceeds the value of this parameter, calculated on the base of the gauge data, for each of all weather stations..

The average values of the correlation coefficients between the measured and estimated monthly precipitation totals are 0.75 and 0.73 , with ranges of $0.64-0.84$ and 0.53-0.81 for GPM IMERG and CHIRPS, respectively. 
The bias parameter values confirm the overestimation of the ground-based monthly precipitation totals by the equivalent RS estimations (with the exception of the CHIRPS estimations at the Chornomorske station). The average bias values are determined as 1.75 and 1.24 , with deviations $1.32-2.12$, and $0.98-1.58$ for GPM IMERG and CHIRPS, respectively.

The ability of the time series RS-estimations to predict the ground-based monthly precipitation totals vary across the RS products, with average efficiency coefficient NSe values of 1.28 and 0.31 and ranges of 2.75 to -0.23 and -0.45 to -0.63 for GPM IMERG and CHIRPS, respectively. The Nash-Scutliff efficiency coefficient values indicate the CHIRPS product as a more effective predictor of the ground-based observed monthly precipitation time series compared to GPM IMERG for all stations (with the exception of the Razdolnoe station, with a negative CHIRPS NSe value).
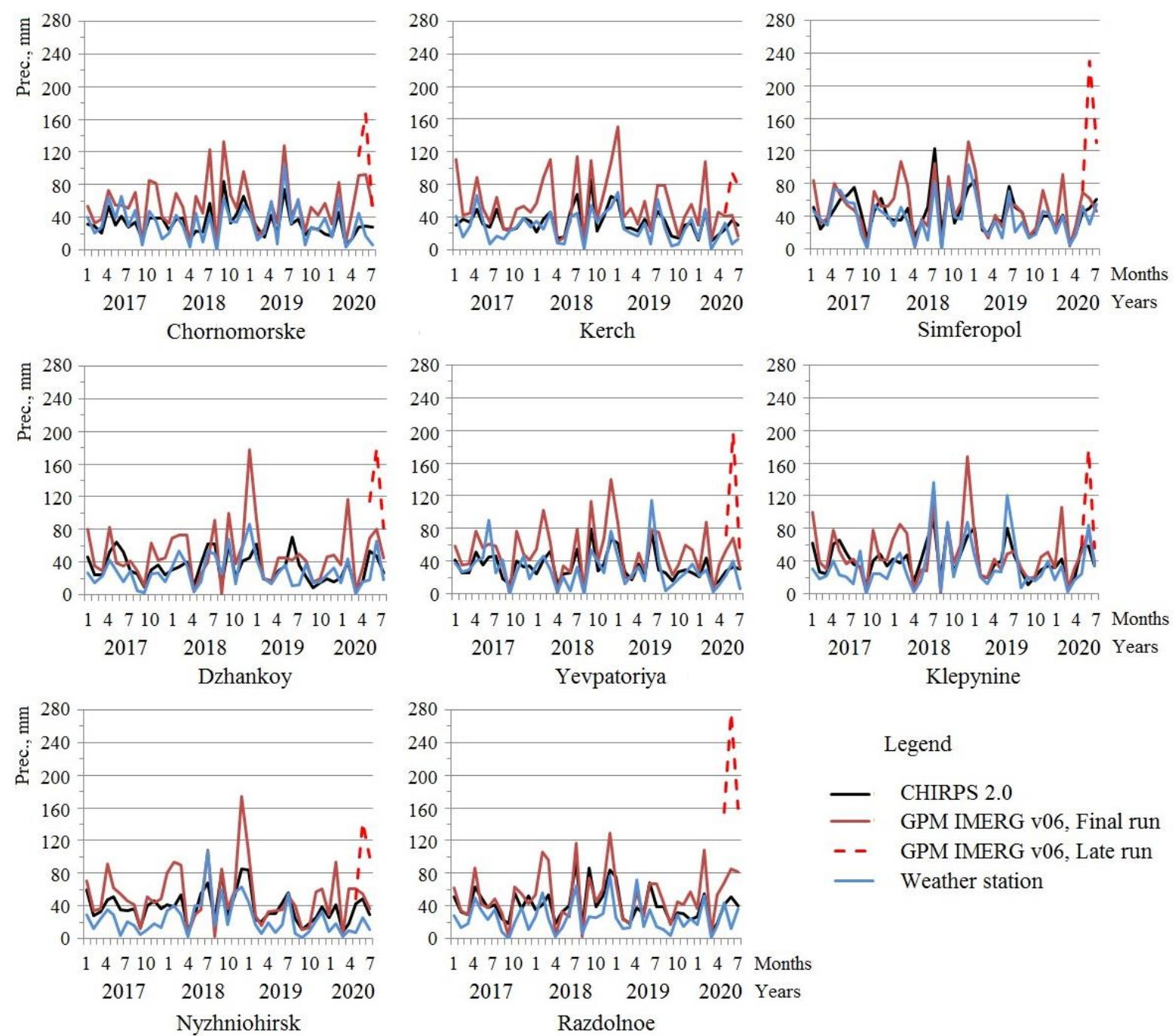

Fig. 3. Monthly variations of ground-based and RS-estimated precipitation. RS products are CHIRPS 2.0 and GPM IMERGM v06 final run across the entire study period and GPM IMERGDL v06 late run for the last three months. 
The level of variation in the precipitation estimated by the CHIRPS and GPM IMERGM final run products compared to the gauge data confirms the statistical analysis presented in Table 2. However, the maximum monthly total precipitation determined by the GPM final run product (corresponding to December 2018 for 6 stations) demonstrates the requirement for additional calibration with the refinement of the resulting estimations for the region.

Considering that the final precipitation estimations determined via the GPM IMERG product have a 3 month delay in availability, the dashed line in Figure 3 allows us to estimate the magnitude of the discrepancy in monthly precipitation totals for the end of the period. The average late run overestimation compared to the final run is determined as $59.2 \mathrm{~mm}$ per month and $88.7 \mathrm{~mm}$ for the entire study period. Furthermore, the maximum deviation of $263.7 \mathrm{~mm}$ per month is observed for the Razdolnoe weather station in June 2020.

\section{Discussion}

The main advantage of precipitation data derived from the satellite measurements in agricultural monitoring tasks is their availability (free open access), high temporal resolution (1-5 days or higher) and improved spatial resolution ( 0.05 and $0.1^{\circ}$ for CHIRPS and GPM IMERG, respectively). The weather station network available in the steppe region of the Crimea does not permit the evaluation of precipitation variations within the districts as there is approximately one station per district. The application of the RSderived precipitation estimations as raster values allow for (taking into account the level of representativeness) an additional 25-30 raster precipitation values for the territory.

Analysis of the relationship between monthly precipitation totals determined via the weather stations and RS products reveal lower values of the determination coefficient (average of 0.52 and 0.56 for CHIRPS and GPM IMERG, respectively) than, for example, for the territory of the Cyprus (Retalis et al. 2018), where the corresponding GPM IMERG determination coefficient exceeds 0.9. A greater correlation can be induced by improving the information availability of precipitation gauge data, where the 3 Crimean WMO weather stations with free open access to data exhibited an almost $20 \%$ higher correlation than other regional stations.

Field rain gauges can aid in evaluating the accuracy of the estimated precipitation spatial distributions determined via the satellite data. However, the level of systematic error for these types of devices can reach 20-30\% (WMO 2008; Villarini et al. 2008), due to the lack of metrological requirements. Moreover, in winter such simplified field rain gauges are removed from the fields. Small and automated weather stations (which often have a solar panel and batteries) have similar drawbacks. Precipitation data collected from such devices may be unavailable and have even higher errors than indicated earlier (WMO 2008) or extensive temporal shifts (via periods of negative temperatures, as well as ice/snow melting times).

The principle disadvantage of the satellite products considered in this work is the 1-1.5 months data lag on the CHIRPS monthly and 5-day precipitation totals and the 3-3.5 month lag on the GPM IMERG final calibrated data (final run). Although the GPM IMERG operational level of the precipitation estimations 
(early run) and intermediate data (late run) are available, the accuracy of these datasets (Fig. 3) does not allow for their direct application in monitoring tasks or for operational and technological decision making.

\section{Conclusions}

We compared the monthly precipitation totals obtained from the GPM_3IMERGM v06 and CHIRPS 2.0 products across period January 2017 - July 2020 with ground-based observations from weather stations located in the steppe region of Crimea. The following key conclusions were made.

The CHIRPS and GPM IMERG products demonstrated, on average, an overestimation of gauged monthly precipitation totals by $6.8 \mathrm{~mm}$ and $21.6 \mathrm{~mm} \cdot \mathrm{month}^{-1}(22 \%$ and $71 \%)$. Furthermore, the average deviation of the precipitation determined from the WMO weather stations were $11 \%$ and $62 \%$, with $30 \%$ and $77 \%$ for other regional weather stations, respectively.

The correlation coefficients between the measured monthly precipitation totals and estimations were determined as 0.75 and 0.73 , for GPM IMERG (final run) and CHIRPS, respectively.

The average absolute deviations of the minimum RS estimated monthly precipitation totals from the ground-based observations were 2.3 and $7.6 \mathrm{~mm}$ for GPM IMERG and CHIRPS, respectively. This is comparable with the accuracy of the soil moisture content measured in the field under common practice in the Crimea that enables to neglect them in agrohydrological calculations.

The two products considered in this paper have distinct advantages and disadvantages based on their spatial and temporal resolution. Synthesizing the favorable features of each products can improve their quality indicators. For example, during a 3-month absence of the GPM IMERG final run data, the CHIRPS data can be employed for 2 months. However, for the last month, further verification and calibration of the daily GPM IMERG data is required for its subsequent application in operational agro-technological decisions.

\section{Acknowledgments}

The reported study was funded by RFBR according to the research project \#19-016-00148 A.

\section{REFERENCES}

Beck H.E., Pan M., Roy T., Weedon G.P., Pappenberger F., van Dijk A.I.J.M., Huffman G.J., Adler R.F., Wood E.F., 2019, Daily evaluation of 26 precipitation datasets using Stage-IV gauge-radar data for the CONUS, Hydrology and Earth System Sciences, 23(1), 207-224, DOI: 10.5194/hess-23-207-2019

Chen S., Zhang L., Zhang Y., Guo M., Liu X., 2020, Evaluation of Tropical Rainfall Measuring Mission (TRMM) satellite precipitation products for drought monitoring over the middle and lower reaches of the Yangtze River Basin, China, Journal of Geographical Sciences, 30, 53-67, DOI: 10.1007/s11442-020-1714-y

Chokngamwong R., Chiu L.S., 2008, Thailand daily rainfall and comparison with TRMM products, Journal of Hydrometeorology, 9, 256-66, DOI: 10.1175/2007JHM876.1

Dembélé M., Zwart S.J., 2016, Evaluation and comparison of satellite-based rainfall products in Burkina Faso, West Africa, International Journal of Remote Sensing, 37(17), 3995-4014, DOI: 10.1080/01431161.2016.1207258 
Dinku T., Funk C., Peterson P., Maidment R., Tadesse T., Gadain H., Ceccato P., 2018, Validation of the CHIRPS satellite rainfall estimates over eastern of Africa, Quarterly Journal of the Royal Meteorological Society, 144(51), 292-312, DOI: 10.1002/qj.3244

Ebert E.E., Janowiak J.E., Kidd C., 2007, Comparison of near real-time precipitation estimates from satellite observations and numerical models, Bulletin of the American Meteorological Society, 88(1), 47-64, DOI: 10.1175/BAMS-88-1-47

Funk C.C., Peterson P.J., Landsfeld M.F., Pedreros D.H., Verdin J.P., Rowland J.D., Romero B.E., Husak G.J., Michaelsen J.C., Verdin A.P., 2014, A quasi-global precipitation time series for drought monitoring, U.S. Geological Survey Data Series, 832, DOI: $10.3133 / \mathrm{ds} 832$

Funk C., Verdin J., Michaelsen J., Peterson P., Pedreros D., Husak G., 2015, A global satellite-assisted precipitation climatology, Earth System Science Data, 7, 275-287, DOI: 10.5194/essd-7-275-2015

Hou A.Y., Kakar R.K., Neeck S., Azarbarzin A.A., Kummerow C.D., Kojima M., Oki R., Nakamura K., Iguchi T., 2014, The global precipitation measurement mission, Bulletin of the American Meteorological Society, 95, 701-722, DOI:

10.1175/BAMS-D-13-00164.1

Huffman G., Bolvin D., Nelkin E., Wolff D., Adler R., Gu G., Hong Y., Bowman K. P., Stocker E., 2007, The TRMM Multisatellite Precipitation Analysis (TMPA): Quasi-global, multiyear, combined-sensor precipitation estimates at fine scales, Journal of Hydrometeorology, 8, 38-55, DOI: 10.1175/JHM560.1

Karthikeyan L., Pan M., Wanders N., Kumar D.N., Wood E.F., 2017, Four decades of microwave satellite soil moisture observations: Part 2. Product validation and inter-satellite comparisons, Advances in Water Resources, 109, 236-252, DOI: 10.1016/j.advwatres.2017.09.010

Kidd C., Levizzani V., Turk J., Ferraro R., 2009, Satellite precipitation measurements for water resource monitoring, Journal of the American Water Resources Association, 45(3), 567-579, DOI: 10.1111/j.1752-1688.2009.00326.x

Liu C., Zipser E.J., 2015, The global distribution of largest, deepest, and most intense precipitation systems, Geophysical Research Letters, 42(9), 3591-3595, DOI: 10.1002/2015GL063776

Liu J., Duan Z., Jiang J., Zhu A., 2015, Evaluation of three satellite precipitation products TRMM 3B42, CMORPH, and PERSIANN over a subtropical watershed in China, Advances in Meteorology, 2015, DOI: 10.1155/2015/151239

Liu Z., Ostrenga D., Teng W., Kempler S., 2012, Tropical Rainfall Measuring Mission (TRMM) precipitation data and services for research and applications, Bulletin of the American Meteorological Society, 1317-1325, DOI: 10.1175/BAMS-D-11-00152.1

Nashwan M., Shahid S., Wang X., 2019, Assessment of satellite-based precipitation measurement products over the hot desert climate of Egypt, Remote Sensing, 11(5), DOI: 10.3390/rs11050555

Ning S., Wang J., Jin J., Ishidaira H., 2016, Assessment of the latest GPM-era high-resolution satellite precipitation products by comparison with observation gauge data over the Chinese mainland, Water, 8(11), DOI: 10.3390/w8110481

Pang J., Zhang H., Xu Q., Wang Yujie, Wang Y., Zhang O., Hao J., 2020, Hydrological evaluation of open-access precipitation data using SWAT at multiple temporal and spatial scales, Hydrology and Earth System Science, 24, 3603-3626, DOI: 10.5194/hess-24-3603-2020

Paredes-Trejo F.J., Barbosa H.A., Kumar T.L., 2017, Validating CHIRPS-based satellite precipitation estimates in Northeast Brazil, Journal of Arid Environment, 139, 26-40, DOI: 10.1016/j.jaridenv.2016.12.009

Retalis A., Katsanos D., Tymvios F., Michaelides S., 2018, Validation of the first years of GPM operation over Cyprus, Remote Sensing, 10(10), 1520, DOI: 10.3390/rs10101520

Saeidizand R., Sabetghadam S., Tarnavsky E., Pierleoni A., 2018, Evaluation of CHIRPS rainfall estimates over Iran, Quarterly Journal of the Royal Meteorological Society, 144(51), 282-291, DOI: 10.1002/qj.3342

Satgé F., Ruelland D., Bonnet M. P., Molina J., Pillco R., 2019, Consistency of satellite-based precipitation products in space and over time compared with gauge observations and snow-hydrological modelling in the Lake Titicaca region, Hydrology and Earth System Science, 23(1), 595-619, DOI: 10.5194/hess-23-595-2019

Scheel M.L., Rohrer M., Huggel C., Villar D.S., Silvestre E., Huffman G.J., 2011, Evaluation of TRMM multi-satellite precipitation analysis (TMPA) performance in the Central Andes region and its dependency on spatial and temporal resolution, Hydrology and Earth System Science, 15(8), 2649-2663, DOI: 10.5194/hess-15-2649-2011 
Tang G., Clark M.P., Papalexiou S.M., Ma Z., Hong Y., 2020, Have satellite precipitation products improved over last two decades? A comprehensive comparison of GPM IMERG with nine satellite and reanalysis datasets, Remote Sensing of Environment, 240, DOI: $10.1016 /$ j.rse.2020.111697

Villarini G., Mandapaka P.V., Krajewski W.F., Moore R.J., 2008, Rainfall and sampling uncertainties: A rain gauge perspective, Journal of Geophysical Research, 113(D11), DOI: 10.1029/2007JD009214

Wang C., Tang G., Han Z., Guo X., Hong Y., 2018, Global intercomparison and regional evaluation of GPM IMERG Version03, Version-04 and its latest Version-05 precipitation products: similarity, difference and improvements, Journal of Hydrology, 564, 342-356, DOI: 10.1016/j.jhydrol.2018.06.064

WMO, 2008, Guide to hydrological practices. Volume I. Hydrology - From measurement to hydrological information, $6^{\text {th }}$ edition, WMO-No. 168, World Meteorological Organization, Geneva, available at http://www.wmo.int/pages/prog/hwrp/publications/guide/english/168_Vol_I_en.pdf (data access 10.08.2020)

Xiao S., Xia J., Zou L., 2020, Evaluation of multi-satellite precipitation products and their ability in capturing the characteristics of extreme climate events over the Yangtze River basin, China, Water, 12(4), DOI: 10.3390/w12041179

Yee M.S., Walker J.P., Rüdiger C., Parinussa R.M., Koike T., Kerr Y.H., 2017, A comparison of SMOS and AMSR2 soil moisture using representative sites of the OzNet monitoring network, Remote Sensing of Environment, 195, 297-312, DOI:

10.1016/j.rse.2017.04.019 